\title{
Yttrium Oxide Nanoparticles Prepared by Heat Treatment of Cathodically Grown Yttrium Hydroxide
}

\author{
Mustafa Aghazadeh, ${ }^{1}$ Mehdi Ghaemi, ${ }^{2}$ Ahmad Nozad Golikand, ${ }^{1}$ \\ Taher Yousefi, ${ }^{1}$ and Esmaeil Jangju ${ }^{1}$ \\ ${ }^{1}$ Material Research School, NSTRI, P.O. Box 14395-836, Tehran, Iran \\ ${ }^{2}$ Department of Chemistry, Science Faculty, Golestan University, P.O. Box 49138-15739, Gorgan, Iran \\ Correspondence should be addressed to Mustafa Aghazadeh, mustafa.aghazadeh@gmail.com
}

Received 11 August 2011; Accepted 7 September 2011

Academic Editors: V. Fruth, Y.-C. Liou, and Y. Waku

Copyright (c) 2011 Mustafa Aghazadeh et al. This is an open access article distributed under the Creative Commons Attribution License, which permits unrestricted use, distribution, and reproduction in any medium, provided the original work is properly cited.

\begin{abstract}
An easy two-step synthetic route is reported for the manufacture of yttrium oxide nanoparticles utilizing aqueous yttrium nitrate solution. In the first step, yttrium hydroxide precursor was grown on stainless steel electrode using a simple cathodic electrodeposition at room temperature. The subsequent second step includes the thermal decomposition of yttrium hydroxide powder at different temperatures for two hours. The synthesized products were characterized by means of X-ray diffraction (XRD), scanning electron microscopy (SEM), differential scanning calorimetery (DSC), FT-IR and Raman spectroscopy. Results showed that the as-deposited $\mathrm{Y}(\mathrm{OH})_{3}$ is composed of nanoparticles with grain size of approximately $40-50$ nm. Cubic-structured $\mathrm{Y}_{2} \mathrm{O}_{3}$ phase with a porous morphology was finally formed when temperature was raised to $600^{\circ} \mathrm{C}$. Results suggested that the final oxide nanoparticles are crystalline and consist only of yttrium oxide phase forming agglomerates of many primary particles with average diameter around $30 \mathrm{~nm}$.
\end{abstract}

\section{Introduction}

Nanosized metal oxides, in a variety of morphologies (such as particles, spheres, rods, and sheets), have attracted a great deal of attention. This is due to their novel physicochemical properties, associated with their nanometer-scale size and excellent technological applications. Yttrium oxide, as an important member among rare-earth compounds, has been actively studied in the recent years. It is one of the most promising elements for the fabrication of optoelectronics devices and chemical catalysis. $\mathrm{Y}_{2} \mathrm{O}_{3}$ can be used as highefficient additives and functional composite materials like yttria stabilized zirconia films [1-4]. This material could be synthesized via several methods, including cathodic electrodeposition [5-9], gas-phase condensation [10], precipitation [11], sol-gel [12], pyrolysis [13], solvothermal [14], and hydrothermal synthesis [15-17]. Among these methods, the easy and clean cathodic electrodeposition method has been proven to be a versatile and controllable technique for the preparation of nanostructured materials.
A variety of important nanoscale metal oxides such as $\mathrm{TiO}_{2}$ [18], $\mathrm{CoO}_{2}$ [19], $\mathrm{Fe}_{2} \mathrm{O}_{3}$ [20], $\mathrm{RuO}_{2}$ [21], $\mathrm{CeO}_{2}$ [22, 23] could be prepared by this method.

Preparation of yttrium oxide by cathodic electrodeposition is simple and inexpensive [9]. In this method yttrium oxide is synthesized by two steps. Firstly, yttrium hydroxide species were grown cathodically on the steel substrate from a bath containing yttrium nitrate solution. The subsequent second step includes the thermal decomposition of yttrium hydroxide to yttrium oxide. In the first step, formation of yttrium hydroxide intermediates is inevitable. These are mainly composed of different yttrium oxide nitrate hydroxides (such as $\mathrm{Y}_{4} \mathrm{O}(\mathrm{OH})_{9}\left(\mathrm{NO}_{3}\right), \mathrm{Y}_{2}(\mathrm{OH})_{5.14}\left(\mathrm{NO}_{3}\right)_{0.86} \cdot \mathrm{H}_{2} \mathrm{O}$, and hexagonal $\left.\mathrm{Y}(\mathrm{OH})_{3}\right)$ [16]. It seems that electrochemical precipitation process of yttrium hydroxide in nitrate salt solution is greatly influenced by nitrate ions. It could be expected that changes of the structural/morphological properties of the prepared yttrium hydroxide precursor may give rise to improved properties and evaluate the important structural and morphological characteristics and enlarge the 
application field of yttrium oxide. These properties can be tuned readily via electrodeposition parameters. In this relation, however, relatively few reports are available in the published literature. As far as the authors know, nanoparticles formed in this way have not been recorded earlier in the literature. Thus, the objective of the present study was to investigate the feasibility of using electrochemical parameters for the preparation and modifications of yttrium hydroxide precursor and synthesis of $\mathrm{Y}_{2} \mathrm{O}_{3}$ nanoparticles. The latter is obtained by heat treatment of the hydroxide precursor, which is cathodically grown on steel substrate in an aqueous yttrium nitrate solution at ambient temperature.

\section{Experimental Procedure}

Electrodeposition experiments were performed using $0.01 \mathrm{M}$ $\mathrm{Y}\left(\mathrm{NO}_{3}\right)_{3} \cdot 6 \mathrm{H}_{2} \mathrm{O}$ (Merck) bath at room temperature. The electrochemical cell includes a cathodic steel substrate centered between two parallel graphite counter electrodes. Prior to each deposition, steel substrates have given an galvanostatically electropolishing treatment at a current density of $20 \mathrm{~A}\left(0.2 \mathrm{~A} \mathrm{~cm}^{-2}\right)$ for $5 \mathrm{~min}$ in a bath $\left(70^{\circ} \mathrm{C}\right)$ containing 50 vol. $\%$ phosphoric acid, 25 vol. $\%$ sulfuric acid, and balanced deionized water. All electrodeposition experiments were performed galvanostatically at a cathode current density of $1 \mathrm{~mA} \mathrm{~cm}^{-2}$ at room temperature. After drying, the as-deposited samples were scraped from the steel electrodes for further characterization and thermal analysis. Crystal structures of the samples were determined by X-ray diffraction (XRD) with a diffractometer (Phillips, PW-1800) using monochromatized $\mathrm{Cu} \mathrm{K} \alpha$ radiation at a scanning rate of $0.5^{\circ} \mathrm{min}^{-1}$. Thermogravimetric analysis (TGA) and thermal behavior of the as-deposited sample were investigated by means of differential scanning calorimeter (DSC, STA-1500). Carbon, nitrogen, and hydrogen contents were determined by $\mathrm{CHN}$ analysis.

The samples were heated in air between room temperature and $600^{\circ} \mathrm{C}$ at a heating rate of $10^{\circ} \mathrm{C} \mathrm{min}^{-1}$. The morphology of the samples was examined using a scanning electron microscopy (Philips 515). Raman and FT-IR spectra were obtained by means of a LAB RAM 800 and a PerkinElmer spectrometer (RX FT-IR), respectively.

\section{Results and Discussion}

Controlling of the reaction rate and the speed of the growth process through experimental parameters including current density, bath temperature, and reaction medium are key factors in designing new products with desired crystallinity and morphologies [24-27]. Preparative parameters such as nature of precipitating agent, nature of rare-earth supplier, and the $\mathrm{pH}$ of the precipitation medium play major roles in physic-chemical characteristics of the precursor [28]. It could be noted that an important aspect in the cathodic electrodeposition process of $\mathrm{Y}(\mathrm{OH})_{3}$ is the reduction of an oxygen precursor at the electrode/solution interface [29]. This would control the growth rate and significantly affects the structural and morphological characteristics of the obtained products.
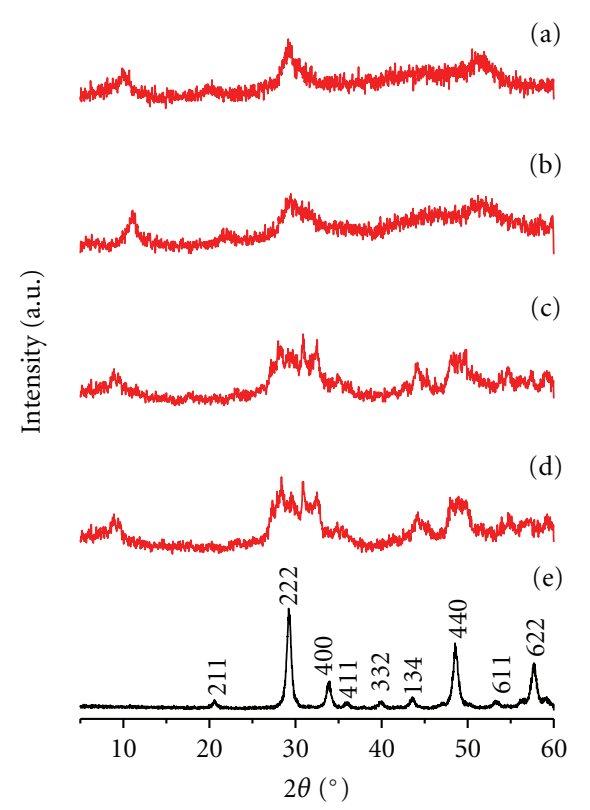

Figure 1: X-ray diffraction patterns of (a) as-deposited $\mathrm{Y}(\mathrm{OH})_{3}$, (b) after thermal treatment at $200^{\circ} \mathrm{C}$, (c) $360^{\circ} \mathrm{C}$, (d) $450^{\circ} \mathrm{C}$, and (e) $600^{\circ} \mathrm{C}$.

Three kinds of oxygen precursor have been reported up to now, that is, nitrate ions, dissolved molecular oxygen, and hydrogen peroxide. Among them, nitrate ions-based oxygen precursor has received considerable interests [30]. The general scheme of electrodeposition of $\mathrm{Y}(\mathrm{OH})_{3}$ from aqueous yttrium nitrate solution could be supposed as follows [31, 32]:

$$
\begin{aligned}
\mathrm{NO}_{3}{ }^{-}+\mathrm{H}_{2} \mathrm{O}+2 \mathrm{e}^{-} & \Leftrightarrow \mathrm{NO}_{2}{ }^{-}+2 \mathrm{OH}^{-}, \\
\mathrm{NO}_{3}{ }^{-}+7 \mathrm{H}_{2} \mathrm{O}+8 \mathrm{e}^{-} & \Leftrightarrow \mathrm{NH}_{4}^{+}+10 \mathrm{OH}^{-}, \\
\mathrm{Y}^{3+}+3 \mathrm{OH}^{-} & \Leftrightarrow \mathrm{Y}(\mathrm{OH})^{3} .
\end{aligned}
$$

Simultaneously, oxidation of water occurs at the anode:

$$
2 \mathrm{H}_{2} \mathrm{O} \Longleftrightarrow \mathrm{O}_{2}+4 \mathrm{H}^{+}+4 \mathrm{e}^{-} .
$$

Cathodic electroreduction of nitrates ions on the electrode surface liberates hydroxide ions known as electrogeneration of base. Then, yttrium ions precipitate with the hydroxyl anions, resulting in the formation of metal hydroxide and yttrium hydroxy-nitrate compounds [33]. Reduction of nitrate ions at the electrode/solution interface controls the growth rate affecting the crystallinity and morphology of the obtained products significantly. Probably, different polarity and hydrogen-bonding ability of the solvent may modify the formation and crystal growth kinetics of the formed nanoparticles. On the other side, the morphological and structural properties of the oxide material could be considered in terms of growth kinetics prevailing during phase conversion of the precursor in the course of annealing. This is due to the fact that some important physicochemical phenomena like structural transformation, volume expansion, release of chemisorbed and physisorbed water are 


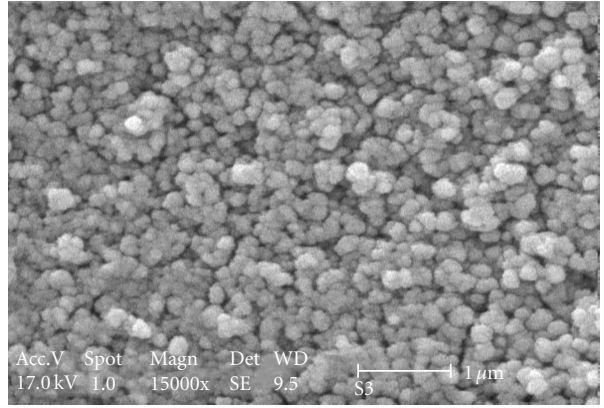

(a)

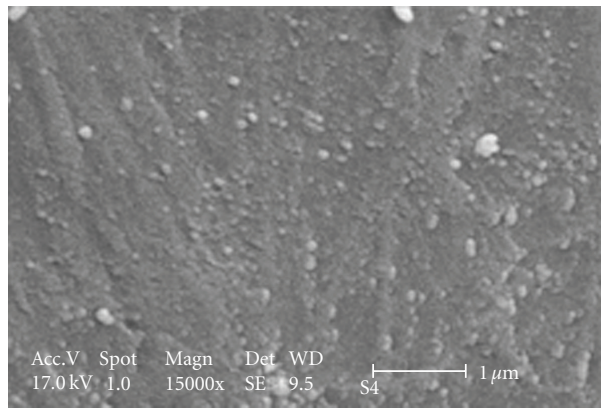

(c)

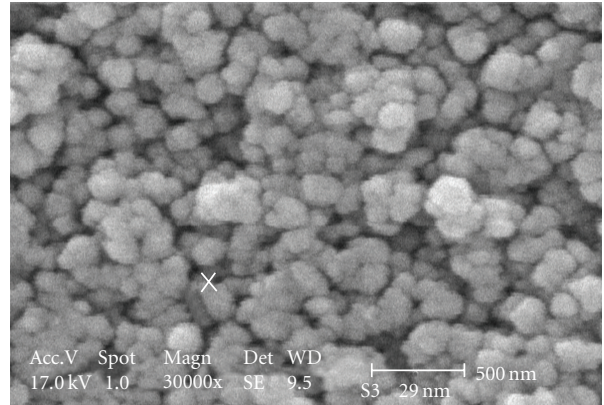

(b)

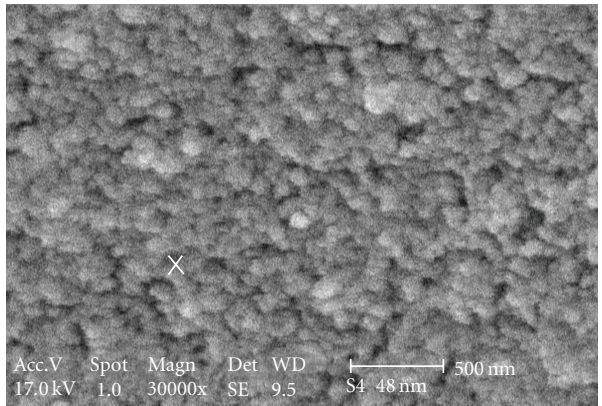

(d)

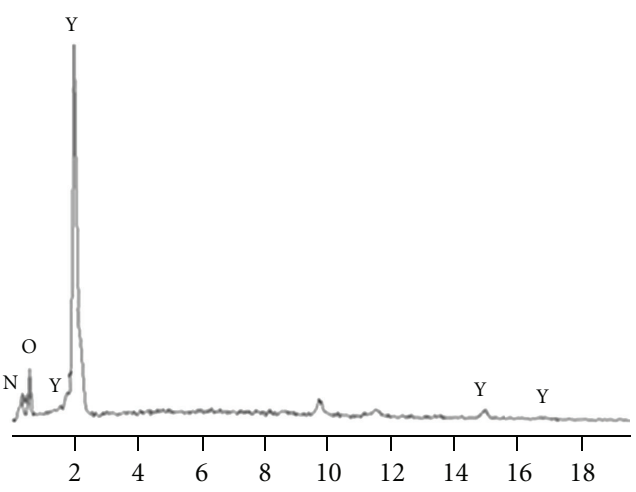

(e)

Figure 2: SEM images of as-deposited sample (a), (b) and $\mathrm{Y}_{2} \mathrm{O}_{3}$ nanoparticles (c), (d). EDAX of as-deposited sample (e).

accompanied with oxidative heat treatment process [34]. The appearance and speed of these phenomena could be described as important factors affecting the properties of oxide nanoparticles.

3.1. Structural and Morphological Characterization. X-ray diffraction patterns have shown that the as-deposited sample was poorly crystallized (Figure 1(a)). This could be explained by crystal growth kinetics under lower bath temperature and the accompanied intercalation of nitrate ions. The existence of nitrate ions in the as-deposited yttrium hydroxide is confirmed by EDAX analysis (Figure 2(e)). XRD patterns of the sample annealed at $600^{\circ} \mathrm{C}$ can be readily indexed to a pure cubic phase of $\mathrm{Y}_{2} \mathrm{O}_{3}$ (Figure 1(e)) [35]. As could be seen in Figure 1, during thermal procedure, $\mathrm{Y}(\mathrm{OH})_{3}$ transformed to various crystallographic patterns at 200, 360,450 , and $600^{\circ} \mathrm{C}$ (Figures 1(b)-1(d)). These compounds mainly consist of different yttrium oxide nitrate hydroxides such as $\mathrm{Y}_{4} \mathrm{O}(\mathrm{OH})_{9}\left(\mathrm{NO}_{3}\right), \mathrm{Y}_{2}(\mathrm{OH})_{5.14}\left(\mathrm{NO}_{3}\right)_{0.86} \cdot \mathrm{H}_{2} \mathrm{O}$, and hexagonal $\mathrm{Y}(\mathrm{OH})_{3}[24]$. Formation and coexistence of such species are strongly depending on experimental conditions such as annealing temperature and $\mathrm{pH}$ of the electrolyte solution. It is reported that the content of hydroxyl group in these compounds may influence the formation temperature of $\mathrm{Y}_{2} \mathrm{O}_{3}$. This temperature is around $530^{\circ} \mathrm{C}$ under our experimental condition as confirmed by DSC analysis (Figure 3 ).

Figure 2 shows SEM images of yttrium hydroxide and that of the annealed sample. EDAX diagram (Figure 2(e)) shows a small amount (approximately 2.5\%) of nitrogen content resulting from accompanied intercalation of nitrate ions in the as-deposited precursor sample. The latter consists of agglomerated particles with diameters around $20-30 \mathrm{~nm}$ (Figures 2(a) and 2(b)). These agglomerates are composed of finer primary particles that coagulate to form larger 


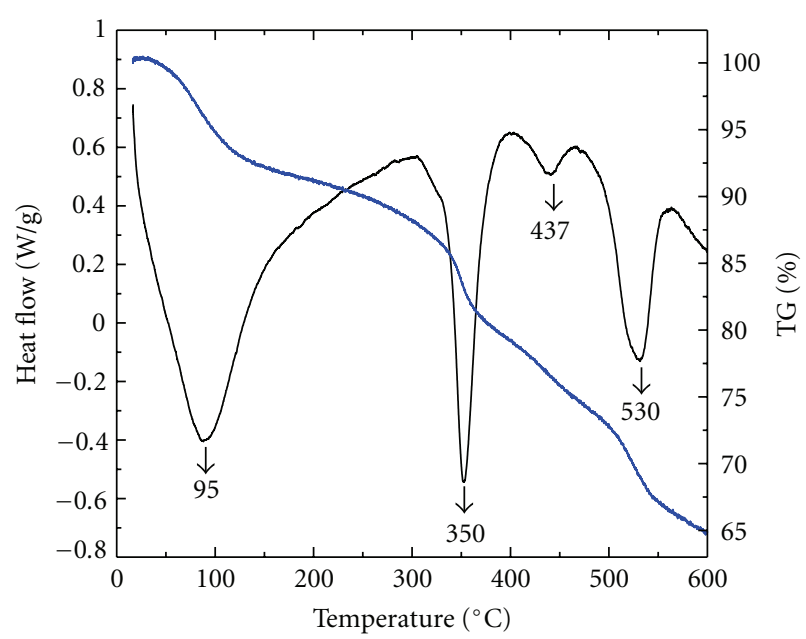

FIgURE 3: DSC/TG analysis of as-deposited $\mathrm{Y}(\mathrm{OH})_{3}$.

particulates. In comparison to $\mathrm{Y}(\mathrm{OH})_{3}$ precursor, it could be clearly seen from Figure 2(c) that the particle size of yttrium oxide is drastically reduced and a more smooth surface was obtained (Figure 2(c)). However, an enlarged SEM image revealed that the oxide film still consists of agglomerated smaller nanoparticles with an average diameters of about 30$40 \mathrm{~nm}$ (Figure 2(d)). This could be related to the phenomena like dehydration and release of $\mathrm{N}-\mathrm{O}$ species which occurs with phase transformations during calcination. These phenomena may cause particles agglomeration.

3.2. Thermal and Spectral Analysis. Figure 3 presents results of thermal DSC and related TG analysis of the as-deposited $\mathrm{Y}(\mathrm{OH})_{3}$ powder. Three endothermic peaks are observed at 95,350 , and $450^{\circ} \mathrm{C}$. The broad endothermic peak around $95^{\circ} \mathrm{C}$ is related to dehydration of free and physically absorbed molecular water. The next endothermic peak at $350^{\circ} \mathrm{C}$ is supposed to be related with the first dehydration of chemisorbed and combined water from $\mathrm{Y}(\mathrm{OH})_{3}$ and $\alpha$ $\mathrm{Y}(\mathrm{OH})_{3}[9,24]$. The endothermic peak at around $450^{\circ} \mathrm{C}$ confirms dehydration of structural water from $\mathrm{YOOH}$ phase $[9,36]$. Decomposition profile of yttrium hydroxide-nitrate compounds is fairly complex with overlapping steps. It is worth noting that $\mathrm{NO}_{3}{ }^{-}$ions and traces of carbonate ions are also present in our samples due to an incomplete precursor wash or by atmospheric $\mathrm{CO}_{2}$ absorption on the gels surface during the precipitation stage [35]. According to [27], ion chromatography analysis indicated that the $\mathrm{NO}_{3}{ }^{-}$content in intermediate products at different calcination steps kept increasing when calcination temperature was lower than $450^{\circ} \mathrm{C}$, while it decreased dramatically during $450-530^{\circ} \mathrm{C}$. It is reported that decomposition of basic yttrium hydroxynitrate $\left[\mathrm{Y}_{2}\left(\mathrm{NO}_{3}\right)_{3} \cdot x \mathrm{Y}(\mathrm{OH})_{3} \cdot y \mathrm{H}_{2} \mathrm{O}\right]$ or hydroxy-carbonate groups $\left[\mathrm{Y}_{2}\left(\mathrm{CO}_{3}\right)_{3} \cdot x \mathrm{Y}(\mathrm{OH})_{3} \cdot y \mathrm{H}_{2} \mathrm{O}\right]$ takes place at temperatures above $500^{\circ} \mathrm{C}$ [33]. Because of presence of these compounds in our hydroxide samples (as justified by EDAX), this result could be consistent with our experimental data showing decomposition temperature of these compounds

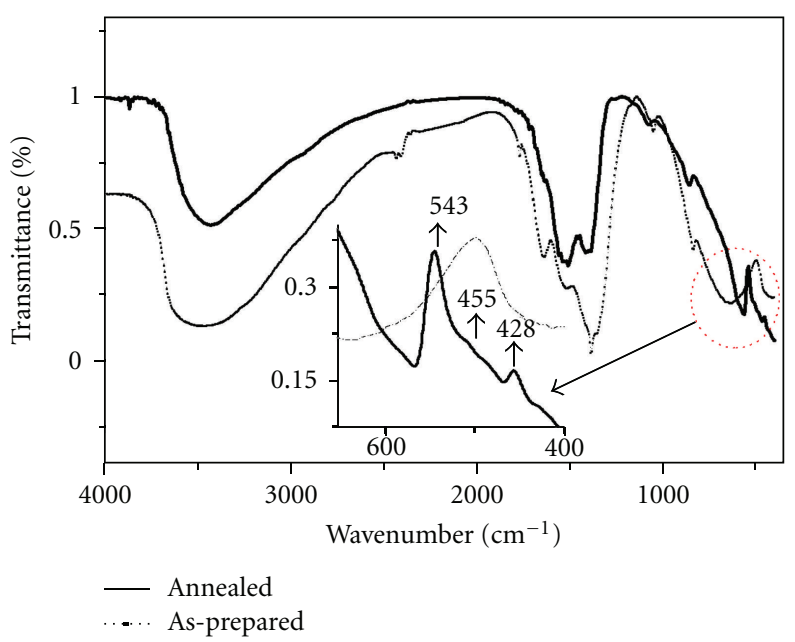

FIGURE 4: FT-IR spectra of the as-prepared $\mathrm{Y}(\mathrm{OH})_{3}$ and annealed at $600^{\circ} \mathrm{C}$.

TABLE 1: CHN analysis results of the as-deposited sample and annealed at $600^{\circ} \mathrm{C}$.

\begin{tabular}{lccc}
\hline Sample type & $\mathrm{C}(\%)$ & $\mathrm{N}(\%)$ & $\mathrm{H}(\%)$ \\
\hline Yttrium hydroxide & 0.25 & 2.72 & 2.34 \\
Yttrium oxide & 0.33 & $\leq 0.03$ & 0.11 \\
\hline
\end{tabular}

and/or the beginning of the yttrium oxide crystallization at $530^{\circ} \mathrm{C}$.

As could be seen from TG diagram, approximately $12 \%$ of the total weight loss corresponds to physically adsorbed water. It can be concluded that the weight loss of $22.5 \%$ below $450^{\circ} \mathrm{C}$ corresponds to the evaporation of physically and chemically adsorbed water and $\mathrm{OH}^{-}$departure, while the weight loss at temperatures higher than $450^{\circ} \mathrm{C}$ (in order of $13 \%$ ) is associated with the release of $\mathrm{N}-\mathrm{O}$ species.

$\mathrm{CHN}$ analysis of as-deposited hydroxide and its annealed sample at $600^{\circ} \mathrm{C}$ was carried out from 25 to $600^{\circ} \mathrm{C}$. The amount of nitrogen in the hydroxide sample did not exceed $2.72 \%$ as shown in CHN analysis result in Table 1 . The nitrogen content of the oxide sample was found to be lower than the detection limit of the instrument (i.e., $\leq 0.03 \%$ ). The intercalation of nitrate ions in electrochemical step is consistent with results of XRD and TG analysis of the hydroxide sample. Results of CHN and EDAX analysis of the latter show the existence of approximately equal amount of nitrogen (Figure 2(e)). Obviously, structural changes of the oxide material, as visible in XRD, could be attributed to the presence and effects of nitrogen during heat treatment process.

FT-IR spectra of the as-prepared $\mathrm{Y}(\mathrm{OH})_{3}$ and that of the annealed one at $600^{\circ} \mathrm{C}$ are shown in Figure 4. IR spectra of our compounds show peaks between 3100 and $3800 \mathrm{~cm}^{-1}$, which may be due to the $\mathrm{O}-\mathrm{H}$ stretching of water molecule [37]. The peaks of $\mathrm{OH}$ stretching vibration appears to be around $3440 \mathrm{~cm}^{-1}$ and vibrations peaks due to intercalated/adsorbed nitrate ions at about $1385 \mathrm{~cm}^{-1}$ [38]. Another peak observed between 1450 and $1670 \mathrm{~cm}^{-1}$ corresponds to the $\mathrm{O}-\mathrm{H}$ bending of water molecules. 


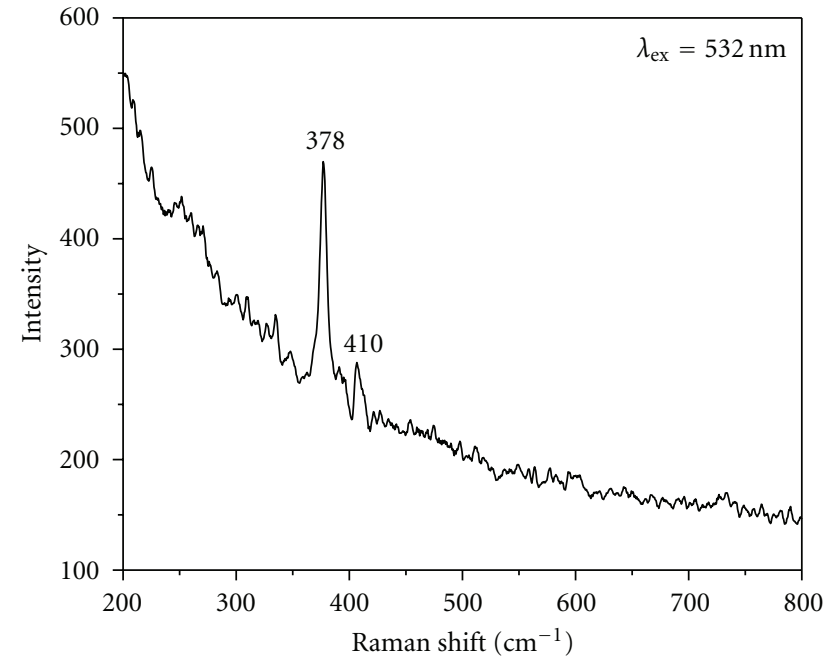

FIgURE 5: Raman spectra of $\mathrm{Y}_{2} \mathrm{O}_{3}$ annealed in air at $600^{\circ} \mathrm{C}$.

The peaks at about $1527 \mathrm{~cm}^{-1}$ and $1407 \mathrm{~cm}^{-1}$ can be attributed to the split antisymmetrical stretching vibration of carbonate and nitrate group, respectively [39]. After the precursor was calcined at $600^{\circ} \mathrm{C}$ for $2 \mathrm{~h}$, new bands at 543 , 455 , and $428 \mathrm{~cm}^{-1}$ appeared (inside graph of Figure 4) [40]. The frequencies below $600 \mathrm{~cm}^{-1}$ could be attributed to $\mathrm{Y}-\mathrm{O}$ stretching mode of $\mathrm{Y}_{2} \mathrm{O}_{3}$ structure.

Figure 5 displays the Stokes Raman spectrum $\left(\lambda_{\mathrm{ex}}=\right.$ $532 \mathrm{~nm}$ ) of $\mathrm{Y}_{2} \mathrm{O}_{3}$ nanoparticles sintered at $600^{\circ} \mathrm{C}$. It shows an intense peak at $378 \mathrm{~cm}^{-1}$ and a weak peak around $410 \mathrm{~cm}^{-1}$. These results are also in agreement with recent reports on Raman spectrum of $\mathrm{Y}_{2} \mathrm{O}_{3}[41,42]$.

\section{Conclusion}

A two-step synthetic route was employed for the synthesis of yttrium oxide nanoparticles under mild conditions. Firstly, $\mathrm{Y}(\mathrm{OH})_{3}$ precursor was cathodically grown on steel substrate in nitrate medium at RT. This is followed by heat treatment of the precursor in air for two hours. The properties of the yttrium hydroxide are strongly influenced by the electrochemical parameters and experimental conditions, which could be tuned to get the desired oxide product after calcination process. During this process, dehydration and structural changes occur, and finally crystalline $\mathrm{Y}_{2} \mathrm{O}_{3}$ could be obtained at $600^{\circ} \mathrm{C}$. The resulting oxide material exhibits nanoparticles with an average particle size of $30 \mathrm{~nm}$. Results of this work showed that adequate adjusting of the electrochemical parameters and bath conditions induce important physicochemical changes of the hydroxide precursor, which translate into important physicochemical changes of the $\mathrm{Y}_{2} \mathrm{O}_{3}$ nanoparticles with desired properties.

\section{References}

[1] S. Ukai and M. Fujiwara, "Perspective of ODS alloys application in nuclear environments," Journal of Nuclear Materials, vol. 307-311, no. 1, pp. 749-757, 2002.
[2] K. Verhiest, A. Almazouzi, N. D. Wispelaere, R. Petrov, and S. Claessens, "Development of oxides dispersion strengthened steels for high temperature nuclear reactor applications," Journal of Nuclear Materials, vol. 385, no. 2, pp. 308-311, 2009.

[3] Z. C. Wang and K. B. Kim, "Fabrication of YSZ thin films from suspension by electrostatic spray deposition," Materials Letters, vol. 62, no. 3, pp. 425-428, 2008.

[4] J. D. Lin, J. G. Duh, and C. L. Lo, "Mechanical properties and resistance to hydrothermal aging of ceria- and yttria-doped tetragonal zirconia ceramics," Materials Chemistry and Physics, vol. 77, no. 3, pp. 808-818, 2003.

[5] J. Lee and Y. Tak, "The preparation of yttrium oxide film deposited by electrochemical method," Journal of Industrial and Engineering Chemistry, vol. 5, no. 2, pp. 139-142, 1999.

[6] I. Zhitomirsky and A. Petric, "Electrochemical deposition of yttrium oxide," Journal of Materials Chemistry, vol. 10, no. 5, pp. 1215-1218, 2000.

[7] I. Zhitomirsky and A. Petric, "Electrolytic deposition of $\mathrm{ZrO}_{2}$ $\mathrm{Y}_{2} \mathrm{O}_{3}$ films," Materials Letters, vol. 50, no. 4, pp. 189-193, 2001.

[8] R. Siab, G. Bonnet, J. M. Brossard, and J. F. Dinhut, "Deposition of yttrium-based thin films on TA6V alloy substrates," Applied Surface Science, vol. 236, no. 1, pp. 50-56, 2004.

[9] M. Aghazadeh, A. Nozad, H. Adelkhani, and M. Ghaemi, "Synthesis of $\mathrm{Y}_{2} \mathrm{O}_{3}$ nanospheres via heat-treatment of cathodically grown $\mathrm{Y}(\mathrm{OH})_{3}$ in chloride medium," Journal of the Electrochemical Society, vol. 157, no. 10, pp. D519-D522, 2010.

[10] Q. Tang, Z. Liu, S. Li, S. Zhang, X. Liu, and Y. Qian, "Synthesis of yttrium hydroxide and oxide nanotubes," Journal of Crystal Growth, vol. 259, no. 1-2, pp. 208-214, 2003.

[11] D. K. Williams, H. Yuan, and B. M. Tissue, "Size dependence of the luminescence spectra and dynamics of $\mathrm{Eu}^{3+}: \mathrm{Y}_{2} \mathrm{O}_{3}$ nanocrystals," Journal of Luminescence, vol. 83-84, pp. 297300, 1999.

[12] R. Subramanian, P. Shankar, S. Kavithaa, S. S. Ramakrishnan, P. C. Angelo, and H. Venkataraman, "Synthesis of nanocrystalline yttria by sol-gel method," Materials Letters, vol. 48, no. 6, pp. 342-346, 2001.

[13] S. Y. Wang and Z. H. Lu, "Preparation of $\mathrm{Y}_{2} \mathrm{O}_{3}$ thin films deposited by pulse ultrasonic spray pyrolysis," Materials Chemistry and Physics, vol. 78, no. 2, pp. 542-545, 2003.

[14] J. A. Nelson and M. J. Wagner, "Yttrium oxide nanoparticles prepared by alkalide reduction," Chemistry of Materials, vol. 14, no. 2, pp. 915-917, 2002.

[15] H. Song, B. Chen, H. Peng, and J. Zhang, "Light-induced change of charge transfer band in nanocrystalline $\mathrm{Y}_{2} \mathrm{O}_{3}: \mathrm{Eu}^{3+}$," Applied Physics Letters, vol. 81, pp. 1776-1778, 2002.

[16] A. J. Rulison and R. C. Flagan, "Synthesis of yttria powders by electrospray pyrolysis," Journal of the American Ceramic Society, vol. 77, no. 12, pp. 3244-3250, 1994.

[17] R. M. Feng, X. J. Yang, W. J. Ji, and C. T. Au, "Hydrothermal synthesis of stable mesoporous $\mathrm{ZrO}_{2}-\mathrm{Y}_{2} \mathrm{O}_{3}$ and $\mathrm{CeO}_{2}-\mathrm{ZrO}_{2}-$ $\mathrm{Y}_{2} \mathrm{O}_{3}$ from simple inorganic salts and CTAB template in aqueous medium," Materials Chemistry and Physics, vol. 107, no. 1, pp. 132-136, 2008.

[18] S. Karuppuchamy and J. M. Jeong, "Super-hydrophilic amorphous titanium dioxide thin film deposited by cathodic electrodeposition," Materials Chemistry and Physics, vol. 93, no. 2-3, pp. 251-254, 2005.

[19] E. A. McNally, I. Zhitomirsky, and D. S. Wilkinson, "Cathodic electrodeposition of cobalt oxide films using polyelectrolytes," Materials Chemistry and Physics, vol. 91, no. 2-3, pp. 391-398, 2005.

[20] J. Cao, I. Zhitomirsky, and M. Niewczas, "Electrodeposition of composite iron oxide-poly(allylamine hydrochloride) films," 
Materials Chemistry and Physics, vol. 96, no. 2-3, pp. 289-295, 2006.

[21] B.-O. Park, C. D. Lokhande, H.-S. Park, K.-D. Jung, and O.$\mathrm{S}$. Joo, "Cathodic electrodeposition of $\mathrm{RuOM}_{2}$ thin films from $\mathrm{Ru}(\mathrm{III}) \mathrm{Cl}_{3}$ solution," Materials Chemistry and Physics, vol. 87, no. 1, pp. 59-66, 2004.

[22] Y. Hamlaoui, L. Tifouti, C. Remazeilles, and F. Pedraza, "Cathodic electrodeposition of cerium based oxides on carbon steel from concentrated cerium nitrate-part II: influence of electrodeposition parameters and of the addition of PEG," Materials Chemistry and Physics, vol. 120, no. 1, pp. 172-180, 2010.

[23] Y. Hamlaoui, F. Pedraza, C. Remazeilles et al., "Cathodic electrodeposition of cerium-based oxides on carbon steel from concentrated cerium nitrate solutions-part I. Electrochemical and analytical characterisation," Materials Chemistry and Physics, vol. 113, no. 2-3, pp. 650-657, 2009.

[24] L. Nan and Y. Kazumichi, "Controlling the morphology of yttrium oxide through different precursors synthesized by hydrothermal method," Journal of Solid State Chemistry, vol. 181, no. 8, pp. 1738-1743, 2008.

[25] F.-K. Liu, Y.-C. Chang, F.-H. Ko, and T.-C. Chu, "Microwave rapid heating for the synthesis of gold nanorods," Materials Letters, vol. 58, no. 3-4, pp. 373-377, 2004.

[26] L. Hui-Hong, L. Ying, and L. Hua-Jun, "Regular microarray of Au flower-like structure formed by template-assisted electrodeposition: influence factors and their electrochemical behavior," Electrochimica Acta, vol. 54, no. 28, pp. 7514-7518, 2009.

[27] L. Yundong, J. Hui, H. Weihua, and T. Hui, "Effects of peak current density on the mechanical properties of nanocrystalline Ni-Co alloys produced by pulse electrodeposition," Applied Surface Science, vol. 254, no. 21, pp. 6865-6869, 2008.

[28] R. Srinivasan, R. Yogamalar, and A. B. Chandra, "Synthesis and structural studies on nanocrystalline yttrium oxide," Advanced Science Letters, vol. 2, pp. 65-69, 2009.

[29] X. Feng, L. Yinong, X. Lili, X. Yan, D. Min, and L. Yunfei, "Seed layer-free electrodeposition of well-aligned $\mathrm{ZnO}$ submicron rod arrays via a simple aqueous electrolyte," Materials Research Bulletin, vol. 44, no. 8, pp. 1700-1708, 2009.

[30] T. Pauporté and D. Lincot, "Hydrogen peroxide oxygen precursor for zinc oxide electrodeposition II-mechanistic aspects," Journal of Electroanalytical Chemistry, vol. 517, no. $1-2$, pp. 54-62, 2001.

[31] I. Zhitomirsky, "Cathodic electrodeposition of ceramic and organoceramic materials. Fundamental aspects," Advances in Colloid and Interface Science, vol. 97, no. 1-3, pp. 279-317, 2002.

[32] B. J. Michel, B. Josseline, C. Juan, and B. Gilles, "Characterization of thin solid films containing yttrium formed by electrogeneration of base for high temperature corrosion applications," Surface and Coatings Technology, vol. 185, no. 23, pp. 275-282, 2004.

[33] L. Muresan, E. J. Popovici, R. Grecu, and L. B. Tudoran, "Studies on the synthesis of europium activated yttrium oxide by wet-chemical method. 1. Influence of precursor quality on phosphor photoluminescence properties," Journal of Alloys and Compounds, vol. 471, no. 1-2, pp. 421-427, 2009.

[34] G. Triantafyllou, G. N. Angelopoulos, and P. Nikolopoulos, "Surface and grain-boundary energies as well as surface mass transport in polycrystalline yttrium oxide," Journal of Materials Science, vol. 45, no. 8, pp. 2015-2022, 2010.

[35] S. Wang, S. Zhong, Z. Wen et al., "Fabrication, annealing, and electrocatalytic properties of platinum nanoparticles supported on self-organized $\mathrm{TiO}_{2}$ nanotubes," Rare Metals, vol. 28, pp. 445-449, 2009.

[36] R. Srinivasan, N. R. Yogamalar, J. Elanchezhiyan, R. J. Joseyphus, and A. C. Bose, "Structural and optical properties of europium doped yttrium oxide nanoparticles for phosphor applications," Journal of Alloys and Compounds, vol. 496, no. $1-2$, pp. 472-477, 2010.

[37] F. Vetrone, J. C. Boyer, and J. A. Capobianco, "Yttrium oxide nanocrystals: luminescent properties and applications," in Encyclopedia of Nanoscience and Nanotechnology, H. S. Nalwa, Ed., vol. 10, pp. 725-765, 2004.

[38] B. E. Prasad, P. V. Kamath, and S. Upadhya, "Electrochemical synthesis of macroporous oxide coatings on stainless-steel substrates," Journal of the American Ceramic Society, vol. 91, no. 12, pp. 3870-3874, 2008.

[39] X. Qin, G. Zhou, H. Yang, Y. Yang, J. Zhang, and S. Wang, "Synthesis and upconversion luminescence of monodispersed, submicron-sized $\mathrm{Er}^{3+}: \mathrm{Y}_{2} \mathrm{O}_{3}$ spherical phosphors," Journal of Alloys and Compounds, vol. 493, no. 1-2, pp. 672-677, 2010.

[40] R. A. Nyquist and R. O. Kagel, Handbook of Infrared and Raman Spectra of Inorganic Compound and Organic Salts, vol. 4, Academic press, Tokyo, Japan, 1997.

[41] A. Ubaldini and M. M. Carnasciali, "Raman characterisation of powder of cubic $\mathrm{RE}_{2} \mathrm{O}_{3}(\mathrm{RE}=\mathrm{Nd}, \mathrm{Gd}, \mathrm{Dy}, \mathrm{Tm}$, and $\mathrm{Lu})$, $\mathrm{Sc}_{2} \mathrm{O}_{3}$ and $\mathrm{Y}_{2} \mathrm{O}_{3}$," Journal of Alloys and Compounds, vol. 454, no. 1-2, pp. 374-378, 2008.

[42] H. Guo and Y. M. Qiao, "Preparation, characterization, and strong upconversion of monodisperse $\mathrm{Y}_{2} \mathrm{O}_{3}: \mathrm{Er}^{3+}, \mathrm{Yb}^{3+}$ microspheres," Optical Materials, vol. 31, no. 4, pp. 583-589, 2009. 

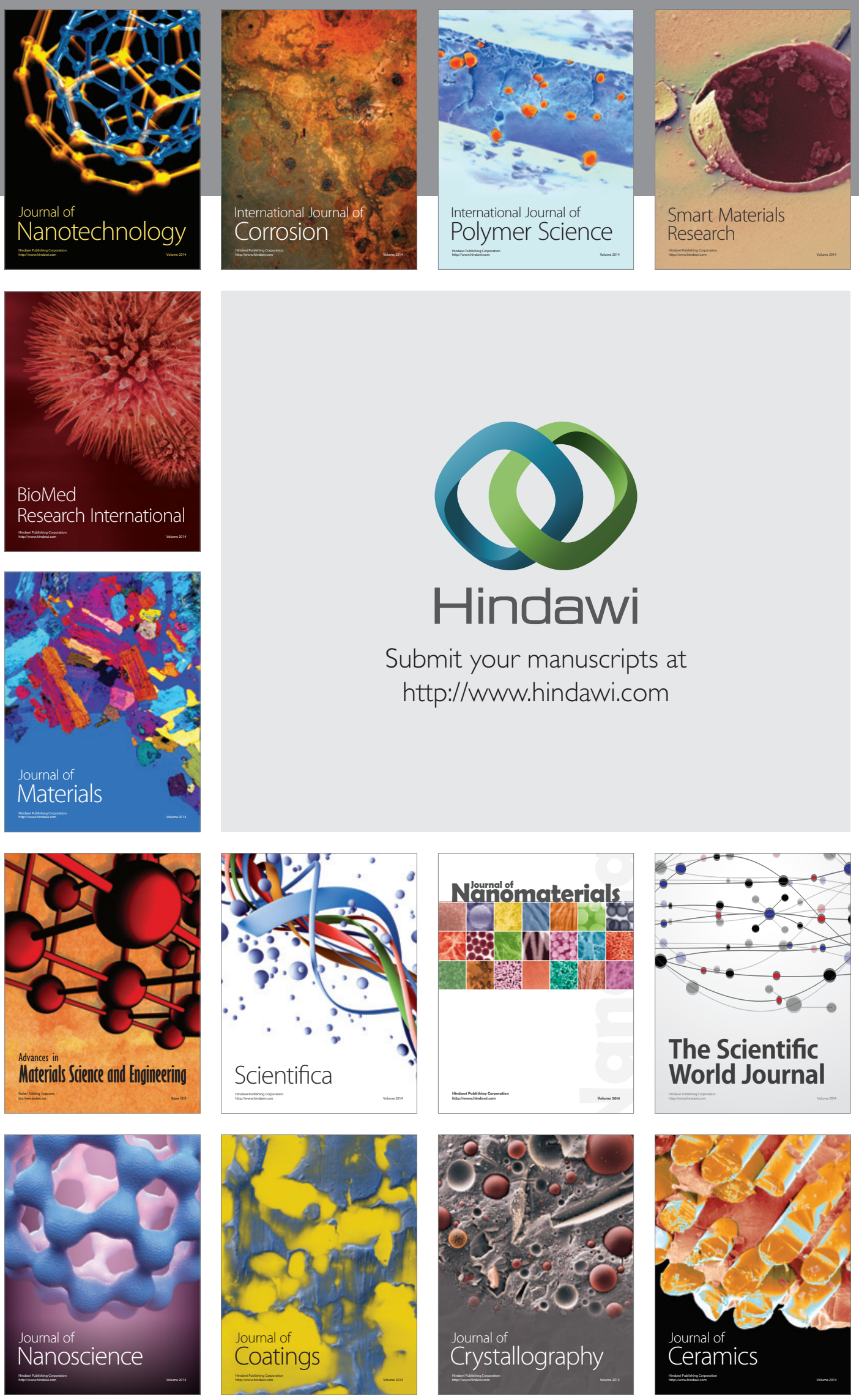

The Scientific World Journal

Submit your manuscripts at

http://www.hindawi.com

\section{World Journal}

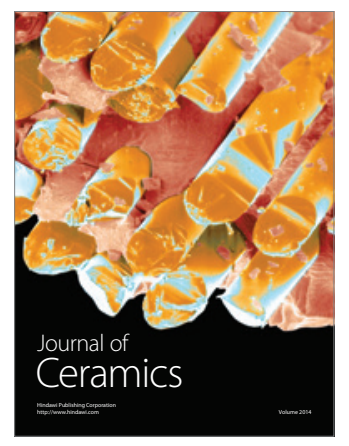

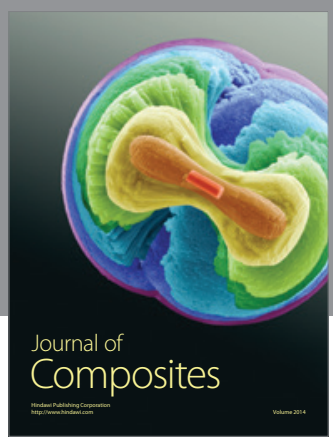
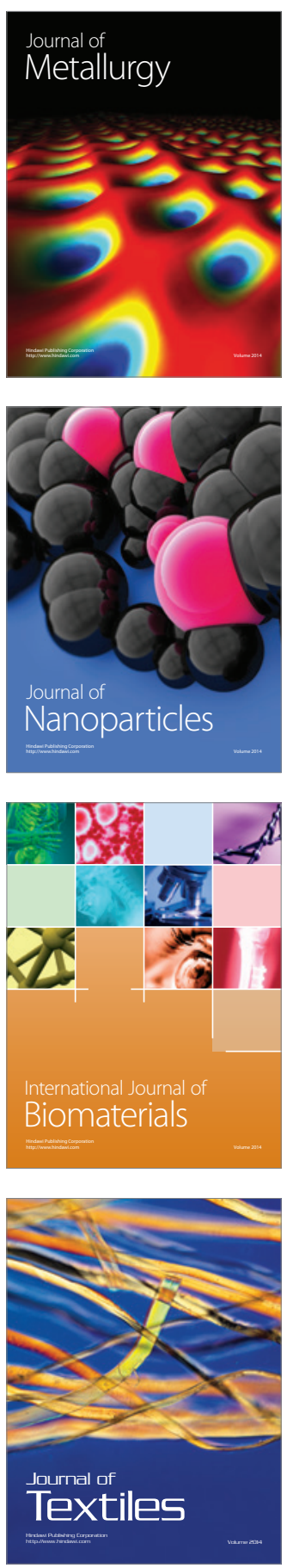